\title{
STRATEGIES THAT CAN HELP TRANSFORM THE CONSTRUCTION INDUSTRY
}

\author{
Margarita Leonova ${ }^{1}$, Glenn Ballard ${ }^{2}$, and Fritz Gehbauer ${ }^{3}$
}

\begin{abstract}
This paper is an appeal to the various stakeholders committed to lean transformation of global construction to coordinate their efforts, and to recruit others not yet committed. Both opponents and advocates of industry transformation are identified; those who live off the waste are in one corner and those who suffer from unsafe, defective, late and costly construction are in the other. A case is made for an alliance of advocates to develop and coordinate the manifold initiatives that together constitute a strategy for transformation.
\end{abstract}

Keywords: Lean construction, industry transformation, research strategies, research areas

\section{INTRODUCTION}

Thee International Group for Lean Construction (IGLC) was formed in 1993 as a platform for academic exchange and lean research. Fifteen papers were presented at the annual conference in 1996. Ten years later, that number had grown to 123. Many of the IGLC papers have been influential in both the academy and practice.

Nevertheless, despite evidence of increasing impact in some parts of the world, it is apparent that the objective of transforming the construction industry is far from being attained. That is even true in countries where Lean has made considerable progress. Moreover, there are major and huge blank areas in the Lean world map, as can be easily deduced from the number of countries not represented in the IGLC conferences. The question has to be discussed whether the IGLC papers in their majority are really supporting the overall objective. There might be even allowed the question whether many of the papers would even frighten away a person from practical life if these papers were their first contact with Lean. In any case, if the success of Lean transformation is suboptimal, then we need a discussion about improved strategies. IGLC researchers could direct some of their research directly to the task of industry transformation; for example, by testing and refuting the paradigms on which traditional, non-Lean practice is based. But research is only one, though a critical one, of the levers for that transformation. In this paper, which does not pretend to be itself a research paper, we provide a larger, more comprehensive view of strategies and stakeholders involved in that initiative.

1 Ph.D. Student, Tallinn University of Technology, Faculty of Civil Engineering, Ehitajate tee 5, 19086 Tallinn, Estonia., +372 5845 4946, margarita.leonova@ttu.ee

2 Research Director, Project Production Systems Laboratory, Civil and Environmental Engineering Dept., Univ. of California, Berkeley, 407 McLaughlin Hall, CA94720-1712, USA. ballard@ce.berkeley.edu

3 Professor Emeritus, Institute for Technology and Management in Construction, Karlsruhe Institute of Technology, Am Fasanengarten Geb. 50.31, 76128 Karlsruhe, Germany, Phone +49-721 9554631, fritzgehbauer@t-online.de 
Others in the IGLC community have addressed issues, challenges and obstacles to Lean Construction adoption, dissemination, research and education and have made recommendations (to mention a few: Alves et al. 2012, Sarhan and Fox 2012, Common et al. 2000, Wandahl 2014). Building on their work, we propose to bring the discussion to a new level.

This paper starts with a summary of observations from a practical view followed by the presentation of strategies for the transformation of the construction industry worldwide. Finally, questions of organizing and developing action pans are discussed.

\section{OBSERVATIONS FROM A PRACTICAL VIEW}

Transforming the construction industry is hindered by existing paradigms and other obstacles. More research is needed to reveal and reduce these obstacles. Many a practitioner having received an introduction to Lean has mentioned that "miracles" like aligning of interests or real and open co-operation are considered impossible. Even companies that have embraced Lean in one or several projects find it hard to maintain the momentum or to develop into a Lean organization. Lean research does not seem to produce answers to those problems. It is mostly concentrated around hypothetical research questions, often far away from practical needs. The traditional administrator usually suspects the idea of Integrated Project Delivery (IPD). The public sector has to be won over and supported in the development of new regulations. The difference between value and low price is not sufficiently understood.

In most countries, Lean education is either totally missing or incomplete. The possibilities of the internet are not explored in that context. If we observe an insufficient Lean education throughout, we have to consider creating a Lean online university.

It is widely accepted that the adoption of lean requires changes in attitudes, thinking, and behaviour. At the same time, it is clear that these changes are hard to achieve and that there are a lot of obstacles. However, too little research action is seen addressing the problems and facilitating the change, especially when different national peculiarities increase the human resistance to change. Too little is done to develop concepts that can drive the change and to identify the drivers.

Often lean is perceived as merely a collection of tools. Sometimes the roles of Lean and BIM are reversed or confused, with BIM even regarded by some as synonymous with Lean. Lean Construction and VDC (Virtual Design and Construction) are often misunderstood to be competing solutions. Why do not VDC and lean always go hand in hand? Newcomers usually have lot of questions and doubts. Lean research does not seem to produce answers to those. Lean needs to join forces with other progressive initiatives in the industry to overcome traditional thinking and mindsets.

The learning culture of the Last Planner System is to a great extent based on learning from failures. The real drive in nature and in humanity is, however, learning from success (Spitzer 2007). This can be systemized and incorporated into Lean.

The majority of all AEC companies belong to the small and medium-sized enterprises (SME) category. Whereas IPD and Alliancing are considered to be of special value in complicated projects, normally not the field of the SME, Lean should make clear what it has to offer to them. Basically, if we promote change within the industry, we have to deal with a huge number of companies with less than 10 employees. Lean construction implementation needs to be evaluated both for its successes and for its omissions.

Stifi (2017) has presented two world maps, one of Transparency International (Corruption Perceptions Index), the other from the World Bank (Control of Corruption). 
A closer look reveals that these countries, with a few exceptions, are the ones with the least adoption of Lean. That is not a surprise. Transparency, open collaboration and reliability have no place in a corrupted system. Endeavours to reduce corruption apply ever more stringent codes and regulations - with no effect. Lean has something else to offer: a gradual entry into a new world with win-win situations.

Stifi (2017) also discusses the fact that corruption and Lean efforts in the same project are hindering each other. Can that be used to reduce corruption? Looking at the corruption world map another interesting observation can be made. Some countries with the lowest corruption factor are very reluctant to embrace full IPD. Possibly, it is feared that corruption could no longer be controlled with these new procurement methods. Any initiative trying to promote Lean has to take such matters into consideration.

Corruption is possibly the number one waste in the industry, but there are more groups that live off waste. In addition, there are the timid ones and persons and organizations resisting change. They all belong to the group of opponents and form obstacles against transformation. On the other hand, there are advocates who have shown considerable success in projects and organizational improvements. They are too few and often regionally confined. A concerted action is needed to spread the success stories and to teach the conditions for success, on a worldwide scale.

\section{STRATEGIES FOR RESEARCH AND EDUCATION}

Even though the construction industry is believed to be slow to adopt innovations and embrace changes, there is a lot going on. The industry is influenced by developments in chemical and materials engineering, construction machinery and equipment, and increasing penetration of ICT (Information and Computer Technology) into daily operations. The Lean Construction community brings management innovations in culture and ways of working. Changing culture and habits is inevitably a slow process and needs a clear strategy and dedication.

Along with other industries, the question for the construction industry is not one of whether or not to innovate but rather of how to do so successfully. The Lean community's goal is for Lean Construction principles and methods to become standard in the industry. The question is how the Lean research community should influence and direct research to achieve the goal.

\subsection{Strategies for research}

During 25 years of extensive research, case studies and conferences the community has produced a Lean Construction body of knowledge. Participants of the 24th IGLC conference discussed where the world is in terms of Lean Construction adoption. Broadly speaking, there has been relatively good progress in terms of lean implementation at the project level; not much evidence of successful lean enterprises; the industry overall has not transformed into a lean one. In other words, it could be said that we have achieved "pockets of excellence"; however, this is not good enough. Using Rogers' Diffusion of Innovations curve to analyse the situation (Rogers 1962), it could be stated that we are still in the "early adopters" phase and in order to reach the "early majority" category we have to "cross the chasm" (Moore 1991). Choosing the right research direction should bring us nearer to achieving the goal.

After about ten years of LC research and implementation, a survey (Common et al. 2000) revealed "a distinct lack of understanding and application of the fundamental techniques required for a lean culture to exist". Nevertheless, more than ten years later 
Alves et al. (2012) discussed the evidence found in the literature and collected from industry actors the variety of ways Lean is understood when applied to construction. A study by Sarhan and Fox (2012) identified three barriers to the successful implementation of LC: [1] Lack of adequate lean awareness and understanding; [2] Lack of top management commitment; and [3] Cultural \& human attitudinal issues. Another research on barriers and obstacles in Lean implementation shows that "the awareness of Lean Construction is considerably low" (Wandahl 2014).

As we all know, there is nothing more practical than a good theory. Apparently, the current best knowledge has not delivered the desirable results. A broader and more fundamental approach in Lean Theory is needed in order to establish a common understanding of key principles and definitions, including lean, value, transformation.

Koskela et al. (2003) argued that while theory explains the reasons and possible preventions of problems, experimentation converts theory into practical methods and tools. Feedback from industry actors along with the appropriate research approach should establish "an appropriate link between theory and practice, strengthening the relevance of academic research" (Rocha et al 2012).

Ultimately, success of lean adoption is seen in the establishment of standard work in AEC companies. IGLC research should definitely consider the environment we are living and working in and have a focus on solving real world problems. At the same time, the proposed solutions should be more universal to avoid unnecessary repetition of the same applications on different companies, regions, countries.

The challenge of promoting partnering between industry and academia has been previously discussed in the work of Alves et al. (2012). Practitioners have the data but do not have the resources to process and analyze it. Researchers, on the other hand, do not have direct access to data but have the capacity to analyze and draw conclusions. Within this win-win collaboration, a transfer of the conclusions and solutions back to the industry in required. For that, publications of academic papers is not sufficient.

During the 24th IGLC conference panel discussions, it was stated that we should find new ways to bring academia and practitioners to work together. Along with a fundamental theory, a simple and clear core concept of Lean should be developed. There should be clarity what the new theory proposes to be done differently and how the proposed solutions are incorporated into the real world and meet the needs of the majority in the field. Examples of successful research-industry partnerships should be taken into consideration. The gap between industry and research is well illustrated in a recent survey (Alves et al. 2016) that highlighted a lack of "pull" from the industry regarding specifying lean skills in job offers, even from members of the Lean Construction Institute.

\subsection{Strategies for education}

Teaching lean concepts is a challenge by itself; however, it pushes lean educators to find creatively different approaches to teaching the subject. Seven different perspectives on teaching LC in a university setting were presented in papers of Tsao et al. (2012) and Tsao et al. (2013). Multiple teaching approaches, e.g. team projects, reading assignments, guest speakers, field trips, mixed with learning methods such as simulations and discussions resulted in higher student engagement and satisfaction in courses. As the leader of the Lean Construction Institute's Academic Forum, Tariq Abdelhamid has collected Lean Construction curricula and materials, which were made available to member companies ${ }^{4}$. Unfortunately, not that many academics followed the encouragement of the authors to

\footnotetext{
${ }^{4}$ The Lean Construction Lighthouse webpage http://www.leanconstruction.msu.edu/
} 
share their teaching approaches, experiences, and lessons learned which leaves some blank spots in the body of knowledge for Lean Construction education.

According to the IGLC statement, in order to respond to the global challenges ahead, the practice, education, and research of the AEC industry have to be radically renewed. Kuhn (1970), writing about paradigmatic change in the sciences, noted that some people are unable to accept and embrace new ways of thinking and behaving. According to Rogers (1962), many of those who did embrace new ways were influenced by innovators and enthusiasts in the field ${ }^{5}$. There is still a lot of work to do in convincing experienced practitioners to go with Lean. However, there are those who do not have to unlearn practices, rather they are ready to think in Lean terms from the beginning. Students and young researchers are going to shape the future of the construction industry in their role as architects, engineers, contractors and owners. In order to compete for the fresh blood and best young brains on the market, the construction industry should think about how to make construction more appealing for students.

The network of research from practice and academia should become more internationalized and its work should be more coordinated. There are still countries and regions that have not heard about lean or are at the very beginning of their journey; however, sometimes more fundamental problems - corruption - must first be addressed. Students and young researchers from those countries should be reached by the representatives of the network of Lean professionals. External advisors should provide guidance and help direct the research to achieve better and faster results, help to avoid beginning from scratch and reproducing research already done.

The authors of this paper discussed several reasons why a new approach to Lean research is needed. Some of the points are reflected in the corresponding IGLC literature. We are hoping to draw additional attention to existing issues and believe that in true collaboration the radical renewal of AEC practice, education and research can be achieved.

Today we have different sources for information about Lean Construction, some of which is outdated. As a community, we have to think about the impression we are making on, for example, newcomers who are searching the web for trusted sources of information. To mention some: the IGLC webpage provides a yearly-replenished collection of conference papers; the Lean Construction Lighthouse was a pioneer effort on making Lean resources available online on a variety of topics; the Lean Construction Institute's website is a good example of a truly helpful get-started source. However, there is no unity for international audience or prospective students and researchers or potential industry actors who would like to partner with academia.

An integrated platform is needed to unite interested parties and enable access to updated information about the lean world. The opportunities and issues that it could address include:

- information about universities that incorporate lean education in their curricula;

- active academia members, their research interests and willingness to serve as external advisors for students;

- students' information ( $\mathrm{CV}$, resume, research interests);

- companies' requests for research support: research questions, data analysis, problems to be solved etc.;

- companies could share achievements and barriers to lean implementation;

\footnotetext{
${ }^{5}$ According to Rogers (1962), (1962) "innovators" initiate the diffusion.
} 
- opportunities for doing case studies, organizing field trips and company tours for students.

The goal is to create a strong network with information collected in one place, easily reachable and accessible for anyone interested in Lean Construction. The platform could address the missing link between research and practice, internationalization, direction and monitoring of quality of the research.

\section{NEED TO CREATE AN ORGANIZATION TO LEAD THIS INITIATIVE: PLAN OF ACTION}

The construction sector is characterized by fragmentation and construction projects by siloed structure. As a result, an age-old question "who must initiate the change?" or "who must demand better construction processes?" has not yet been answered. It seems that the lean movement also lacks a shared view of the direction and general steps towards lean at the industry-level.

Lean Construction is said to need a greater sense of mission, focus, and industry support (Forbes and Ahmed 2011). We invite interested parties to participate in creating a plan of action. We list some elements that need to be considered:

- Producing a fundamental Lean Theory with clearly defined terminology and agreed definitions (what is lean, value, change etc.) and key principles.

- Research revealing how Lean can help attack fundamental obstacles like corruption.

- Opportunities for several relevant research focuses can be distinguished: research on obstacles to lean transformation; observation and description of real-world problems and paradigms; observation and description of what is working and why it is working during the lean journey.

- Exploring other industries for useful input to the lean transformation of construction. Interesting parallels were drawn in the recent paper about filmmaking and construction (Ballard et al. 2016).

- A new direction should be set in order to boost interest and trust of traditional academia and increase number of proceedings in other non-lean conferences and journals, and stimulate externally generated citations of IGLC papers. (More statistics on citations can be found in the work of Pasquire and Connor (2011).

- A plan for attracting young people to the construction industry as practitioners and researchers.

- Collaborate really collaborate to make Lean Construction a global movement:

- Establish a strong integrated network (a platform) of representatives of research, education, practice and potential members of the Lean Community.

- Create internet-based Lean Construction courses, the nucleus of a later internet Lean University.

The construction industry strongly impacts the economies of almost every country, through spending in both the public and private sector, and fundamentally through changing the built environment. We need an improved next level of performance. The term "next level" refers to ideas that could improve the impact of construction on society 
and the environment. Advocates for Lean Construction will start from different places. What's critical is for them to reach their next level of understanding and application from whatever base they start. That includes politicians, public clients, the industry and universities. Groups already practicing Lean and collaborative contracting are invited to join the discussion with the aim to reach a "next level" of performance: The International Group of Lean Construction (IGLC), the Lean Construction Institutes worldwide, the Alliancing community of Australia, the Integrated Project Delivery (IPD) projects in the US, the Lean in the Public Sector (LIPS) conferences worldwide, and organizations that develop and promote BIM and other information technologies, such as BuildSmart and BIM Forum.

The IGLC community cannot alone develop an action plan and create the organizational base for the actions needed. However, IGLC can take a leadership role in bringing advocates for Lean Construction together, and solicit research that facilitate construction industry transformation. The following action plan includes the important contributions IGLC can make. But it is not limited to those. This paper is addressing the IGLC community because many of the key players in the action plan should come from that community. Many of its members and contributors belong to influential organizations both in the academic and industry world. We invite them to join in an effort to initiate actions and create organizational structures that are necessary for transforming the construction industry. Nevertheless, we also need working groups and organizational structures. These cannot be created in one stroke. But a beginning has to be made.

The beginning could be a working group consisting of influential stakeholders of IGLC. Its first task could be to bring in more stakeholders and to form an alliance of advocates to develop and coordinate the manifold initiatives that together constitute a strategy for transformation.

\section{SUMMARY AND CONCLUSIONS}

This paper has outlined an approach to lean transformation of the construction industry. Needs and opportunities for change have been identified and first steps proposed, including creation of a leadership group drawn from multiple stakeholders. The role envisioned for IGLC as an organization is to be part of the industry transformation leadership, focused on issues of research and education.

\section{REFERENCES}

Alves, T.D.C.L., Azambuja, M.M. and Arnous, B. (2016). Teaching Lean Construction: A Survey of Lean Skills and Qualifications Expected by Contractors and Specialty Contractors in 2016. Proceedings of the 24th Annual Conference of the International Group for Lean Construction.

Alves, T.D.C.L., Milberg C., Walsh, K.D. (2012). Exploring lean construction practice, research, and education. Engineering, Construction and Architectural Management. Vol. 19 No. 5, pp. 512 - 525

Ballard, G., Egebjerg, C., Bølviken, T., Endresen, S. and Ballard, B. (2016). Filmmaking and Construction: Two Project Production Systems. Proceedings of the 24th Annual Conference of the International Group for Lean Construction.

Common, G., Johansen, E. and Greenwood, D. (2000). A Survey of the Take-Up of Lean Concepts Among UK Construction Companies. Proceedings of the 8th Annual Conference of the International Group for Lean Construction. 
Forbes, L.H. and Ahmed, S.M. (2010). Modern Construction Lean Project Delivery and Integrated Practices. Boca Raton, FL, CRC Press Taylor \& Francis.

Koskela, L., Ballard, G. and Howell, G. (2003). Achieving Change in Construction. Proceedings of the 11th International Group for Lean Construction Conference.

Kuhn, T.S., (1970) The structure of scientific revolutions. International Encyclopedia of Unified Science, vol. 2, no. 2.

Moore, G.A. (1991). Crossing the Chasm. Harper Perennial.

Pasquire, C. and Connor, P. (2011). Where does the Theory Informing the International Group for Lean Construction Come From? Proceedings of the 19th Annual Conference of the International Group for Lean Construction.

Rocha, C.G.D., Formoso, C.T., Tzortzopoulos-Fazenda, P., Koskela, L. and Tezel, A. (2012). Design Science Research in Lean Construction: Process and Outcomes. Proceedings of the 20th Annual Conference of the International Group for Lean Construction.

Rogers, E.M. (1962). Diffusion of Innovations. The Free Press, New York.

Sarhan, S. and Fox, A. (2012). Trends and Challenges to the Development of a Lean Culture Among UK Construction Organisations. Proceedings of the 20th Annual Conference of the International Group for Lean Construction.

Stifi, A. (2017). Development of an Anti-Corruption Toolkit with Components of Lean Construction. Doctoral Dissertation submitted to the Institute for Technology and Management in Construction, KIT.

Spitzer, M (2007) Learning: The Human Brain and the School of Life. Elsevier Science

The IGLC webpage http://www.iglc.net/

The Lean Construction Lighthouse webpage http://www.leanconstruction.msu.edu/

The Lean Construction Institute's website https://www.leanconstruction.org/

Tsao, C.C., Alves, T.D.C.L. \& Mitropoulos, P. (2012). Different Perspectives on Teaching Lean Construction. Proceedings of the 20th Annual Conference of the International Group for Lean Construction.

Tsao, C.C., Azambuja, M., Hamzeh, F.R., Menches, C. \& Rybkowski, Z.K. (2013). Teaching Lean Construction Perspectives on Theory and Practice. P. Proceedings of the 21th Annual Conference of the International Group for Lean Construction.

Wandahl, S. (2014). Lean Construction with or without Lean - Challenges of Implementing Lean Construction. Proceedings of the 22nd Annual Conference of the International Group for Lean Construction. 